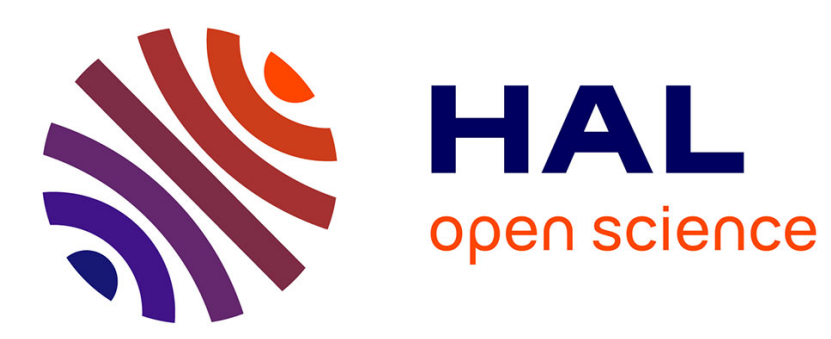

\title{
Characterization of a pressure measuring system for the evaluation of medical devices
}

\author{
Rébecca Bonnaire, Marion Verhaeghe, Jérôme Molimard, Paul Calmels, \\ Reynald Convert
}

\section{- To cite this version:}

Rébecca Bonnaire, Marion Verhaeghe, Jérôme Molimard, Paul Calmels, Reynald Convert. Characterization of a pressure measuring system for the evaluation of medical devices. Proceedings of the Institution of Mechanical Engineers, Part H: Journal of Engineering in Medicine, 2014, 228 (12), pp.1264-1274. 10.1177/0954411914562871 . hal-01137411

\section{HAL Id: hal-01137411 \\ https://hal.science/hal-01137411}

Submitted on 30 Mar 2015

HAL is a multi-disciplinary open access archive for the deposit and dissemination of scientific research documents, whether they are published or not. The documents may come from teaching and research institutions in France or abroad, or from public or private research centers.
L'archive ouverte pluridisciplinaire HAL, est destinée au dépôt et à la diffusion de documents scientifiques de niveau recherche, publiés ou non, émanant des établissements d'enseignement et de recherche français ou étrangers, des laboratoires publics ou privés. 


\section{Characterization of a pressure measuring system for the evaluation of} medical devices

$5 \quad$ Rébecca Bonnaire ${ }^{1,2^{*}}$, Marion Verhaeghe ${ }^{3}$, Jérôme Molimard ${ }^{1}$, Paul Calmels ${ }^{4}$ and Reynald 6 Convert $^{2}$

$7 \quad{ }^{1}$ LGF, UMR 5307, École Nationale Supérieure des Mines, CIS-EMSE, CNRS, Saint-Etienne, France

$8 \quad{ }^{2}$ Thuasne, Levallois-Perret, France

$9 \quad{ }^{3}$ Université de Technologie de Compiègne, Compiègne, France

$10{ }^{4}$ Université de Lyon, Laboratoire de Physiologie de l'Exercice, F-42023, Saint-Etienne, France

* Corresponding author :

13 Rébecca Bonnaire, LGF, UMR 5307, Ecole Nationale Supérieure des Mines de Saint-Etienne, CS 62362,

14 F-42023 Saint-Etienne cedex 2, France

15 Email : bonnaire@emse.fr

16 


\section{Abstract}

18 The purpose of this study is to evaluate the possible use of four "FSA" thin and flexible resistive pressure 19 mapping systems, designed by Vista Medical (Winnipeg, Manitoba, Canada), for the measurement of 20 interface pressure exerted by lumbar belts onto the trunk. These sensors were originally designed for the measurement of low pressure applied by medical devices on the skin.

Two types of tests were performed: standard metrology tests such as linearity, hysteresis, repeatability, reproducibility and drift, and specific tests for this application such as curvature, surface condition and mapping system superposition. The linear regression coefficient is between 0.86 and 0.98 ; hysteresis is between $6.29 \%$ and $9.41 \%$. Measurements are repeatable. The location, time and operator, measurement surface condition and mapping system superposition have a statistically significant influence on the results. A stable measure is verified over the period defined in the calibration procedure, but unacceptable drift is observed afterward. The measurement stays suitable on a curved surface for an applied pressure above $50 \mathrm{mmHg}$. to avoid drift. Moreover, when comparing different measurements with this sensor the location, the time, the operator and the measurement surface condition should not change; the mapping system must not be superimposed.

\section{Keywords}




\section{Introduction}

39 Low back pain is a major public health problem in developed countries. In France, prevalence of low back pain is higher than $50 \%$ [1]. Because of health care costs and sick leave [1-2], low back pain has

41 adverse consequences on both the social and economic level. Many treatments have been proposed.

42 However, no guidelines are proposed to practitioners, particularly for chronicle evolution. Treatment propositions and success depend on the patient comportment, on the aetiology and/or mechanical causes of low back pain, on the evolution along the time and also on the physician's opinions. Lumbar belts are frequently proposed to treat low back pain. Several clinical trials have shown their clinical effectiveness [3-4]. Nevertheless, both the mechanical and the physiological effects of lumbar belts remain unclear.

47 It is assumed that the main mechanical effect of lumbar belts is the pressure applied on the trunk; therefore it has been decided to investigate experimentally this pressure. In the medical field, pressure measurement is already used to evaluate devices employed to prevent bedsores [5-11], to measure the interface pressure of compression stockings, compression bandages [12-18] and rigid orthosis [19-20]. Using pressure measurement to mechanically characterize lumbar belts can be considered as new approach.

53 Four types of interface pressure sensors exist: pneumatic (Example: PicoPress ${ }^{\odot}$, St Neots 54 Cambridgeshire, United Kingdom), electro-pneumatic (Example: Salzmann ${ }^{\odot}$, St. Gallen, Switzerland), resistive (Example: Tekscan $^{\odot}$, Boston MA, USA) or capacitive (Example: X-Sensor ${ }^{\odot}$, Calgary Alberta,

56 Canada or Novel $^{\odot}$, Munich Germany) sensors. Resistive or capacitive sensors may be assembled into a

57 structure that enables the pressure to be measured at several points simultaneously; this structure is often

58 called a pressure mapping system.

59 In this study, four identical FSA ${ }^{\oplus}$ pressure mapping systems were chosen and purchased $\left(\right.$ Vista Medical $^{\odot}$,

60 Winnipeg Manitoba, Canada). They are composed of resistive sensors, based on the piezoresistive 
61 properties of some materials. The resistivity of piezoresistive materials varies according to the forces 62 exerted on this material. Resistivity is proportional to the electrical resistance which is converted into 63 voltage. After calibration, measurement of voltage enables the interface pressure to be measured [21]. 64 These pressure mapping systems were chosen because they are thin and compliant, free from error of 65 measurement on curved surfaces, sensitive in detecting a range of pressure as low as $0-100 \mathrm{mmHg}(0-$ $6613.3 \mathrm{kPa}$ ), in accordance to in-vivo studies (free from temperature or moisture effects, dynamic range $\geq 10$ $67 \mathrm{~Hz}$ ) and give indications of pressure gradients in a context of spatial variations of support stiffness and 68 shape [22-24]. Compared to the capacitive sensors, resistive sensors have a lower drift and are less expensive [25-26].

70

71 Aim of this study is to evaluate these four identical pressure mapping systems, particularly in challenging applications such as lumbar belts. This evaluation is performed by two types of tests:

- classical tests of metrology such as linearity, hysteresis, repeatability, reproducibility and drift,

- $\quad$ specific test for the application developed in this study, such as curvature, surface condition and mapping system superposition.

The goal of classical tests is to determine the proper functioning of sensors in their general use. The goal of specific tests is to characterize the pressure sensors in case of interface pressure measurement between the trunk and the lumbar belt. Actually, in this specific type of measurement, surfaces are soft and curved. Moreover, the four pressure mapping systems may be partially superimposed during the measurement. 


\section{Methods}

\section{The FSA pressure mapping systems}

85 Four mapping systems are needed to measure the interface pressure all around the trunk. In this study, the 86 mapping systems will be tested all together and no comparison between them will be done. Pressure 87 mapping systems are composed of 12 by 32 piezoresistive sensors. Each sensor is a square with sides measuring $7.9 \mathrm{~mm}$, separated by $4.2 \mathrm{~mm}$. The active area is 382 by $142 \mathrm{~mm}$. The total size of the mapping system is 482 by $242 \mathrm{~mm}$. Sensor calibration is performed with the pressure range from 0 to $100 \mathrm{mmHg}$. During calibration, $50 \mathrm{mmHg}$ is measured for 60 seconds to compensate the drift effect. The FSA pressure mapping system is illustrated in Figure 1. The pressure mapping systems are denoted below A, B, C and D.

$94 \quad$ Classical tests of metrology [27]

95 Linearity test. For the linearity test, seven cylindrical steel weights were designed to apply pressure between 6 and 96mmHg on one sensor. Weights were randomly applied in sensors 1, 2 and 3 (see Figure

97 1). Thirty measurements were carried out for each sensor. The linear regression coefficient $R^{2}$ between applied and measured pressures, the dispersion and the standard deviation $\mathrm{s}_{\mathrm{p}}$ were calculated. The linear regression coefficient $\mathrm{R}^{2}$ is defined by the following formula:

$100 \quad R^{2}=\frac{\operatorname{cov}\left(P, P_{i}\right)^{2}}{\operatorname{var}(P) \operatorname{var}\left(P_{i}\right)}$ with $\mathrm{P}$, the measured pressure value in $\mathrm{mmHg}$ and $\mathrm{Pi}$, the applied pressure value in $\mathrm{mmHg}$.

102 The dispersion is defined as the difference between the maximum and the minimum pressure measured for each applied pressure. The standard deviation $s_{p}$ of the measured pressure is defined by the following formula: 
with $\mathrm{n}$, the size of the measured sample and $\mathrm{P}$, the measured pressure value for each applied pressure in mmHg.

108 Hysteresis test. Two types of hysteresis tests were performed: an hysteresis test in only one sensor and an hysteresis test in all sensors at the same time of the mapping system.

110 For the first test, the same weights as for the linearity test, were increasingly and decreasingly applied on

111 eight sensors. The position of these sensors is represented in Figure 1. For the second test, pressure 112 mapping was placed on an air pocket and introduced between two wooden planks. Figure 2 illustrates this 113 experimental device. The air pocket was inflated to apply increasing then decreasing pressure between 10 114 and $100 \mathrm{mmHg}$ to the mapping system.

115 Hysteresis is defined by the following formula:

$116 \quad E_{h}(\%)=\frac{\left|y_{d\left(x_{i}\right)}-y_{m\left(x_{i}\right)}\right|}{x_{i}} * 100$

117 with $\mathrm{x}_{\mathrm{i}}$, the discrete values of applied pressure in $\mathrm{mmHg}, \mathrm{y}_{\mathrm{m}}$ the measured pressure value during the 118 increasing phase corresponding to a given $\mathrm{x}_{\mathrm{i}}$ in $\mathrm{mmHg}$, and $\mathrm{y}_{\mathrm{d}}$ the measured pressure value during the 119 decreasing phase corresponding to a given $\mathrm{x}_{\mathrm{i}}$ in $\mathrm{mmHg}$.

120 Repeatability test. The repeatability of experiments was assessed by performing the first hysteresis test 121 three times. Repetitions were compared by statistical analysis as explained in paragraph 2.4.

122 Reproducibility test. The reproducibility of time, location and operators was tested. The first hysteresis 123 test was performed in two different rooms, by two different operators and at two different times separated 124 by two months. 
125 A specific design of experiments was used to evaluation reproducibility (Table 1). In this design of 126 experiments, there are four independent factors: location, time, operators and weight applied to the 127 mapping system. The interactions between each factor are considered. The selected design of experiments 128 is factorial and follows this polynomial model:

$129 P=\sum_{i} \beta_{i} x_{i}+\sum_{i j} \beta_{i j} x_{i} x_{j}$

130 with $\mathrm{P}$, the measured pressure $(\mathrm{mmHg}), \beta_{\mathrm{i}}$ or $\beta_{\mathrm{ij}}$, the polynomial coefficients and $\mathrm{x}_{\mathrm{i}}$ or $\mathrm{x}_{\mathrm{j}}$, the input factor of the design of experiments.

132 Drift test. To determine if the pressure recorded changes over time, four weights corresponding to 26,40 , 13352 and $80 \mathrm{mmHg}$ applied pressure were left on 1, 2, 3, 4, 5 and 6 sensors (see Figure 1) for a duration 134 higher than that of the calibration to drift (30 minutes).

135 For each case, the range of stored drift, as defined by the minimum and maximum pressures measured 136 during the testing, was determined. The relative pressure variation was expressed by the following 137 formula:

$138 \Delta P_{r}=\frac{\left|P_{m}-P_{a}\right|}{P_{a}}$

139 with $\Delta P_{r}$ the relative pressure variation, $P_{m}$ the measured pressure and $P_{a}$ the applied pressure.

140 Tests specific to the application

141 Curvature test. An experimental setup was developed to characterize the impact of measurement on 142 curved surfaces. This experimental setup consists in a support on which it is possible to place cylinders of 143 different radii. Radii used in this study were 60, 80, 100 and $125 \mathrm{~mm}$. Pressure mapping systems were placed on the cylinder. Pressure was applied on one single line of sensors using a $15 \mathrm{~mm}$ band, at the end of which weights were hung on. This experimental setup is illustrated in Figure 3. Three lines were tested 
146 for one mapping system. As results were similar for these three lines, just one line was tested for the other

147 three pressure mapping systems. Six or seven different pressures were applied per cylinder, per line and 148 per pressure mapping system.

149 For each applied pressure, cylinder and pressure mapping system, normalized pressure was calculated 150 according to the following formula:

$151 \quad P_{n}=\frac{P_{m}}{P_{a}}$

152 with $P_{n}$ the normalized pressure, $P_{m}$ the measured pressure and $P_{a}$ the applied pressure.

153 Surface condition test. The possible application of this system is to measure the interface pressure applied 154 by lumbar belts. Usually these belts are worn over garments (tee shirt, shirts, etc.). The surface condition 155 of the measured zone is important. Two different surface conditions have been tested. Evaluation of the 156 effect of the surface condition was done in two stages.

157 Firstly, a hysteresis test was performed with only one sensor and seven different medical fabrics placed 158 between the table and the mapping system. For two of the tested fabrics, the pressure decrease was more than $50 \%$. Therefore, these two fabrics were not considered for the statistical analysis. For the other five 160 fabrics, two statistical analyses were performed. The first one was used to compare results with and without fabric between the pressure mapping system and the table. The second one was used to determine

162 if results are different depending on fabrics inserted between the table and the pressure mapping system.

163 Secondly, the hysteresis test was conducted with only one sensor with weights surrounded by silicone and 164 with froth positioned between the table and the mapping system. Statistical analysis was done to determine if there are statistical significant differences between results for this test and for the first test of hysteresis (test in one sensor). The linear regression coefficient was calculated thanks to equation 1. 
167 Mapping system superposition test. To determine the impact of two superimposed pressure mapping

168 systems on the results, the first hysteresis test (test in one sensor) was performed in three sensors stacking 169 two mapping systems.

170 Statistical analysis was performed to determine if there are statistical significant differences between

171 results for the pressure mapping system "from above" and the pressure mapping system "from the 172 bottom". Absolute differences between measured pressures with or without superposition were calculated 173 for each pressure mapping system.

$174 \quad$ Statistical analysis

175 Statistical analysis was used to determine differences between two or more than two distributions.

176 Depending on the number of data sets to compare, two types of statistical approach were used. A Jarque-

177 Bera test was used to check whether or not data matched normal distribution.

178 To compare two sets of data, a Student t-test was used if they were distributed following a normal 179 distribution, and a Wilcoxon signed ranks if not. The statistical analysis of two distributions was used for 180 mapping system superposition and surface condition tests. Student t-test was also used for the linearity test to determine if the linear regression curve's slope is zero.

182 To compare more than two sets of data, an ANOVA was used if they were all distributed following a 183 normal distribution, and a Kruskal-Wallis test if not. If needed, the post-hoc test of Tukey was used to 184 find which of the data sets were different. The statistical analysis of more than two distributions was used 185 for repeatability and surface condition tests.

186 All the statistical tests were performed with a risk $\alpha$ to be equal or smaller than $5 \%$.

\section{Results}

\section{Classical tests of metrology}


Linearity. Linear regression coefficients and p-value of the Student's test on slope $=0$ are given in Table 2.

190 The results are illustrated for one sensor of one mapping system in Figure 4. The linear regression 191 coefficient $\mathrm{R}^{2}$ is between 0.86 and 0.98 depending on the sensor and the mapping system. The maximum 192 dispersion and the maximum standard deviation to the measured pressure are 18.9 and $9.60 \mathrm{mmHg}$ respectively. Table 3 shows the results of maximum dispersion and maximum standard deviation for sensors with the best and the worst linearity.

Hysteresis. All results are given in Table 4. For the first test of hysteresis (test in only one sensor), hysteresis is between $0.228 \%$ and $27.9 \%$. An example of results for the second hysteresis test (test in all sensors of a pressure mapping system) is given in Figure 5. For this test of hysteresis, the hysteresis is between $6.29 \%$ and $9.41 \%$. All results are given in Table 5 .

Repeatability. The Kruskal-Wallis test shows no difference ( $\mathrm{p}$-value $=0.88$ ). Measurements are repeatable.

Reproducibility. Table 6 indicates the polynomial coefficient of the experimental design model and probability that the factor $x_{i}$ has at least a $95 \%$ chance of not significantly affecting the response to pressure of the sensors. $x_{i}$ can be time, space, operators, weight or interactions factors. The biggest polynomial coefficient corresponds to the weight influence and the smaller corresponds to the time influence. Location, weight, time coupling with operators and time coupling with location have statistical influence to the measured pressure.

Drift. No significant drift was observable during the first 60 seconds, i.e. the calibration time for drift. After that period, three types of drift are obtained: measured pressure increases during the first few minutes and becomes stable, measured pressure decreases during the first few minutes and becomes stable and measured pressure is stable over time. Figure 6 represents these three typical results. For all sensors, measured pressure becomes stable and reaches its nominal value after 800 seconds. 
214 Curvature. Figure 7 shows results for the mapping pressure system A. The results depend on the applied 215 pressure. When the applied pressure is less than $50 \mathrm{mmHg}$, the measured pressure is lower than the 216 applied pressure. Nevertheless, when the applied pressure is more than $50 \mathrm{mmHg}$, the difference between 217 the applied pressure and the measured pressure is minor.

218 Surface condition. The probabilities of there being at least a 95\% chance that results with and without 219 fabric between the pressure mapping system and the table are different for the five tested fabrics are given 220 in Table 7. All fabrics have a statistically significant influence on the results.

221 The Kruskal-Wallis test is significant ( $\mathrm{p}$-value $<0.001$ ). The five fabrics are statistically significantly 222 different. Only measured pressure for fabrics 1 and 2, 3 and 4, and 3 and 5 do not have a statistically significant difference.

224 For the second surface condition test, the linear regression coefficient $\mathrm{R}^{2}$ is between 0.95 and 0.99 , depending on the sensor and the mapping system. Hysteresis is between $4.2 \%$ and $15 \%$. For the third surface condition test, the linear regression coefficient $\mathrm{R}^{2}$ is between 0.92 and 0.98 . Detailed results for the second and third tests are presented in Table 8 . Mapping system superposition. Mapping system superposition results consist of two distributions: measured pressure for the mapping systems "from above" and for the mapping systems "from the bottom".

Results for the test of Wilcoxon signed rank, to compare results for the mapping systems "from above" and "from the bottom", are given in Table 9. Table 10 indicates absolute differences between measured pressures with or without superposition for each pressure mapping system. 


\section{Discussion}

237 In this study, four identical pressure mapping systems were evaluated in term of linearity, hysteresis, reproducibility and drift. Some other evaluations demonstrated the efficacy of the pressure mapping systems in the specific application of lumbar belts characterization. According to the results, pressure mapping systems are suitable for this application.

241 We found that linearity is acceptable according to the linear regression coefficient $\mathrm{R}^{2}$ which is always 242 greater than 0.85 . Pressure measured with sensors is always underestimated. The maximum deviation is $24315.4 \mathrm{mmHg}$. The hysteresis of the pressure mapping system depends on sensors. On the whole, hysteresis 244 is low between $6.29 \%$ and $9.41 \%$. Measurements are repeatable. The reproducibility test shows the 245 influence of experimental location, time and operator; the most influencing parameter is the location. 246 According to the drift test, the value remains stable if the measuring time remains lower than the drift 247 calibration time, but dramatically changes afterward.

248 Thanks to our tests specific to the application, it is possible to conclude that curvature test results depend on the applied pressure. For applied pressure higher than $50 \mathrm{mmHg}$, measurement is the same as on a flat surface. Nevertheless, for applied pressure less than $50 \mathrm{mmHg}$, the measured pressure is lower than the applied pressure. This can be explained by the experimental device. It is supposed that the band sticks on the cylinder when the applied pressure is too low and the pressure estimation from Laplace's law is not valid any more. Thus, no conclusions to the impact of curvature for low measured pressure can be drawn from these results.

We also proved that the surface measurement has a significant influence on the measured pressure. However, there is no change in hysteresis and linearity when pressure is measured between two soft surfaces. In this case, hysteresis is between $4.2 \%$ and $15 \%$ and the linear regression coefficient is between 

on the measurement.

Metrological results of other sensors have been collected from the literature: Flexiforce ${ }^{\circledR}$ [22], F-Socket ${ }^{\odot}$ [25] and F-Scan ${ }^{\odot}$ [21] sensors from Tekscan ${ }^{\odot}$, Rincoe's sensor [25] and Lück sensor [29]. Measurement error and hysteresis are summarized in Table 11. For accuracy, FSA sensor is identical (Flexiforce ${ }^{\circledR}$, FSocket $^{\circledR}$ ) or even better (Rincoe, Lück, F-Scan ${ }^{\circledR}$ ) than other pressure mapping systems. For hysteresis, performances of other resistive sensors are identical $\left(\right.$ Flexiforce $\left.^{\Theta}\right)$ or lower $\left(\mathrm{F}-\right.$ Socket $^{\Theta}$, Rincoe) than the $\mathrm{FSA}^{\odot}$ sensor. Measurement is repeatable for all resistive sensors [22-23]. Other resistive sensors drift as well: Flexiforce sensors' measurements increase or decrease with time [22] [26]; Rincoe SFS and FSocket $^{\circledR}$ from Tekscan ${ }^{\circledR}$ sensors' measurements increase with time [21] [25]. The increase or decrease of the measurement varies from $7.4 \%$ to $11.9 \%$ in twenty minutes [25]. According to the literature, the curvature of the measurement surface has an influence, for other resistive sensors than FSA ${ }^{\oplus}$ sensor on the measurement regardless of the pressure range. The sensitivity of the Tekscan ${ }^{\Theta}$, Flexiforce $^{\odot}$ sensor is modified with radius of curvature [22]. For Rincoe SFS and F-Socket ${ }^{\circledR}$ sensors from Tekscan $^{\circledR}$, accuracy decreases, drift error increases and hysteresis can increase or decrease with radius of curvature [25]. No data was found to compare the $\mathrm{FSA}^{\odot}$ sensor with other resistive sensors in term of reproducibility, surface condition and superposition of two pressure mapping system.

279 It is also possible, according to data from the literature, to compare the FSA ${ }^{\oplus}$ sensors with other types of pressure mapping systems for measuring interface pressure: the $\mathrm{X}$-Sensor ${ }^{\oplus}$ capacitive pressure mapping 
281 system [21, 28, 29] and Novel $^{\odot}$ distributed sensors [23]. For linearity, the X-Sensor ${ }^{\odot}$ is linear [28] and 282 measures $75.1 \%$ of the applied pressure [21]. The capacitive sensor may demonstrate a worse 283 performance than FSA $^{\oplus}$. The maximum measurement error for X-Sensor ${ }^{\odot}$ is $65 \%$ of applied pressure or $28427 \mathrm{mmHg}$ [29]. Novel ${ }^{\odot}$ 's sensor demonstrates a superior performance: its linear coefficient is 0.997 and 285 the measurement error is less than $1 \mathrm{mmHg}$ [23]. But capacitive sensors have a greater hysteresis than 286 resistive sensors. For example, the $\mathrm{X}$-Sensor ${ }^{\odot}$ hysteresis is $14 \%$ [28]. Measurement with capacitive 287 sensors is repeatable [23-24]. According to the drift test, measured pressure with capacitive sensors 288 increases with time [21] [26]. Concerning the surface condition, capacitive sensors, X-Sensor ${ }^{\odot}$ and $289 \mathrm{Novel}^{\odot}$, allow better or worse measurement on soft surfaces depending on the thickness of these surfaces 290 [28]. No data was found to compare the $\mathrm{FSA}^{\odot}$ sensor with capacitive sensors in terms of reproducibility, curvature and superposition of two pressure mapping systems.

292

Considerations on the use of FSA ${ }^{\circledR}$ pressure mapping system for the clinical study of lumbar belt

294 Based on these results, it is necessary to take into account some points to develop the experimental protocol. First, to be accurate, measurement must be done in the same place and preferably by the same operator and in short time frame. It's easy to perform measurement in the same place, but it's more difficult, in a clinical field, to respect the two other points, because measurements is often done by more than one experimenter and it's difficult to find enough subjects in a short time frame. However, these two parameters have influence on the results with coupled parameters. Secondly, drift result shows the importance in the choice of the drift calibration period, drift being uncontrolled if the measuring time is higher. Actually, during calibration, the central value of the calibration interval is measured for a flexible period. Pressure mapping system was calibrated in this study with a flexible period of 60 seconds, but the period can be increased to more than 800 seconds to avoid drift. This solution permits to perform dynamic measurements. Third, improving the curvature test is necessary before beginning the clinical 
305

306

307

study to ensure that the measurement of low pressure will be accurate on curved surfaces. Fourthly, surface condition having an influence on the results, pressure measurements will be done between lumbar belts and a tee-shirt of the same composition for all experiments and all subjects. Whatever the surface condition, pressure measurement remains accurate in term of linearity and hysteresis. Finally, the pressure mapping systems will be used to never overlap while covering the whole trunk. To overcome the difficulty of this condition, measures will be taken side by side. All these conditions allow a suitable measurement of pressure and to compare pressure applied by lumbar belt in term of lumbar belt's types and patient's morphology.

To conclude, the $\mathrm{FSA}^{\odot}$ sensor performance can be considered as better than other resistive sensors and demonstrates an identical performance to the capacitive sensor X-Sensor ${ }^{\odot}$ with lower hysteresis. Nevertheless, the capacitive sensor Novel demonstrates a better performance than the FSA $^{\odot}$ sensor, but has a higher drift effect. FSA ${ }^{\odot}$ sensors can be a good choice for the future clinical study developed to measure the static pressure applied by the lumbar belt on the trunk, because this study will be done in the same place, in a short time frame, with the same operator, with no overlapped mapping system and between same types of surface. Indeed, the procedure described earlier with $\mathrm{FSA}^{\odot}$ pressure mapping system still lacks of robustness for a routine clinical practice to evaluate pressure applied by lumbar belts prescribed to the low back pain patients.

\section{Conclusion}

In this study, four $\mathrm{FSA}^{\oplus}$ pressure mapping systems were characterized in term of linearity, hysteresis, repeatability, reproducibility, drift, curvature, surface condition and mapping system superposition. It was found that these pressure mapping systems are suitable for our application: pressure measurement between two soft surfaces, lumbar belt and the human trunk. Linearity, accuracy and hysteresis are 
328 adequate. Measurement is repeatable and suitable on a flat surface. The curvature of the surface

329 measurement has no significant impact on the measured pressure.

330 However, it is necessary to take into account some recommendations before performing measurements

331 with this $\mathrm{FSA}^{\oplus}$ sensor. To compare the results of different experiments, measurement must be performed

332 in the same place, over a short timeframe, with the same operator. Calibration must be adapted to prevent

333 sensor drift. The measurements shall concern the same type of surface. Moreover, it is important to avoid

334 overlap of pressure mapping systems.

335 Further study is needed to evaluate the performance of the sensor on a curved surface when applied pressure is lower than $50 \mathrm{mmHg}$ and also how the sensor behaves when temperature and humidity change.

Acknowledgements

339 The authors would like to thank Mr. Poirier for his assistance with this work.

\section{Conflict of interest}

342 There is no conflict of interest in this study.

\section{Funding:}

345 This research received no specific grant from any funding agency in the public, commercial, or not-forprofit sectors.

\section{References} S41. French 
351 2. Leclerc A, Gourmelen J, Chastang JF, Plouvier S, Niedhammer I, Lanoë JL. Level of education and

352 back pain in France: the role of demographic, lifestyle and physical work factors. Int Arch Occup Environ

353 Health 2009; 82(5): 643-652.

354 3. Calmels P, Galtier B, Carzon JG, Poinsignon JP, Vautravers P, Delarque A. Etude de l'effet antalgique 355 et fonctionnel du port d'une orthèse lombaire souple dans la lombalgie aiguë. Annales de Réadaptation et 356 de Médecine Physique 1999; 42(6): 333-340.

357 4. Calmels P, Queneau P, Hamonet C, Le Pen C, Maurel F, Lerouvreur C, Thoumie P. Effectiveness of a 358 lumbar belt in subacute low back pain: an open, multicentric and randomized clinical study. Spine 2009; 34(3): $215-220$.

360 5. Vaisbuch N, Meyer S, Weiss PL. Effect of seated posture on interface pressure in children who are able-bodied and who have myelomeningocele. Disabil Rehabil 2000; 22(17): 749-755.

6. Fenety PA, Putnam C, Walker JM. In-chair movement: validity, reliability and implications for measuring sitting discomfort. Appl Ergon 2000; 31(4): 383-393.

364 7. Shelton F, Lott JW. Conducting and interpreting interface pressure evaluations of clinical support 365 surfaces. Ger Nursing 2003; 24(4): 222-227.

366 8. Tam EW, Mak AF, Lam WN, Evans JH, Chow YY. Pelvic movement and interface pressure 367 distribution during manual wheelchair propulsion. Arch Phys Med Rehabil 2003; 84(10): 1466-1472. sitting behavior: interface pressure distribution and subcutaneous tissue oxygenation. J Rehabil Res Dev 2009; 46(5): 577-586. 
371 10. Rithalia SV, Heath GH, Gonsalkorale M. Assessment of alternating-pressure air mattresses using a

372 time-based pressure threshold technique and continuous measurements of transcutaneous gases. J Tissue

373 Viability 2000; 10(1): 13-20.

374 11. Hamanami K, Tokuhiro A, Inoue H. Finding the optimal setting of inflated air pressure for a multi375 cell air cushion for wheelchair patients with spinal cord injury. Acta Med. Okayama 2004; 58(1): 37-44.

376 12. Partsch H, Partsch B, Braun W. Interface pressure and stiffness of ready made compression stockings: 377 comparison of in vivo and in vitro measurements. J Vasc Surg 2006; 44(4): 809-814.

378 13. Hafner J, Lüthi W, Hänssle H, Kammerlander G, Burg G. Instruction of compression therapy by 379 means of interface pressure measurement. Dermatol Surg 2000; 26(5): 481-486.

380 14. Damstra RJ, Brouwer ER, Partsch H. Controlled, comparative study of relation between volume 381 changes and interface pressure under short-stretch bandages in leg lymphedema patients. Dermatol Surg $382 \quad 2008 ; 34(6): 773-778$.

383 15. Damstra RJ, Partsch H. Compression therapy in breast cancer-related lymphedema: A randomized, 384 controlled comparative study of relation between volume and interface pressure changes. J Vasc Surg $3852009 ; 49(5): 1256-1263$.

386 16. Dumbleton T, Buis AWP, McFadyen A, McHugh BF, McKay G, Murray KD, Sexton S. Dynamic 387 interface pressure distributions of two transtibial prosthetic socket concepts. J Rehabil Res Dev 2009; 46(3): 405-415. a Chinese population. Burns 2010; 36(8): 1234-1241. 
391 18. Reich-Schupke S, Gahr M, Altmeyer P, Stücker M. Resting pressure exerted by round knitted 392 moderate-compression stockings on the lower leg in clinical practice--results of an experimental study. 393 Dermatol Surg 2009; 35(12): 1989-1997.

394 19. van den Hout JAAM, van Rhijn LW, van den Munckhof RJH, van Ooy A. Interface corrective force 395 measurements in Boston brace treatment. Eur Spine J 2002; 11(4): 332-335. 20. Aubin CE, Labelle H, Cheriet F, Villemure I, Mathieu PA, Dansereau J. Évaluation tridimensionnelle et optimisation du traitement orthopédique de la scoliose idiopathique adolescente. MS. Médecine Sciences 2007; 23(11): 904-909.

21. Fergenbaum MA, Hadcock L, Stevenson JM, Bryant JT, Morin E, Reid SA. Development of a 400 dynamic biomechanical model for load carriage: Phase 4, Part C2: Assessment of Pressure Measurement 401 Systems on Flat Surfaces for the Dynamic Biomechanical Model of Human Load Carriage. Contract Report, Queen's University, Kingston, Ontario, Canada. 2005; 33p. 22. Ferguson-Pell M, Hagisawa S, Bain D. Evaluation of a sensor for low interface pressure applications. Med Eng Phys 2000; 22(9): 657-663.

405 23. Lai CHY, Li-Tsang CWP. Validation of the Pliance X System in measuring interface pressure generated by pressure garment. Burns 2009; 35(6): 845-851.

407 24. Chiang CC, Lin CCK, Ju MS. An implantable capacitive pressure sensor for biomedical applications. Sens Actuators A Phys 2007; 134(2): 382-388. two commercial pressure sensor systems for prosthetic socket fit. Prosthet Orthot Int 2000; 24(1): 63-73. 
411 26. Wheeler JW, Dabling JG, Chinn D, Turner T, Filatov A, Anderson L, Rohrer B. MEMS-based bubble 412 pressure sensor for prosthetic socket interface pressure measurement. Conf Proc IEEE Eng Med Biol Soc $413 \quad 2011 ; 2925-2928$.

414 27. BIPM, IEC, IFCC, ILAC, IUPAC, IUPAP, ISO, OIML. The international vocabulary of metrology415 basic and general concepts and associated terms (VIM), 3rd edn. JCGM 200:2012.

416 28. Hochmann D, Diesing P, Boenick U. Evaluierung der Messmethoden zur Bewertung des 417 Therapeutischen nutzens von Antidekubitus-Systemen. Biomed Tech 2002;47(suppl 1 pt 2):816-819.

418 29. Völker HU, Rölker N, Willy C. Auflagedruckmessung in der Dekubitusbehandlung. Anaesthesist $4192006 ; 55(2): 142-147$.

420 
422 Table 1. Design of experiments to test the reproducibility of time, place and operators

423 Table 2. Results of linearity: linear regression coefficient

424 Table 3. Results of linearity: dispersion and standard deviation for sensor 1 and mapping system C

425 Table 4: Results of hysteresis: test in only one sensor per mapping system

426 Table 5. Results of hysteresis: test in all sensors per mapping system

427 Table 6. Results of the design of experiments for reproducibility. t: time, o: operators, l: location, w:

428 weight

429 Table 7. Results of surface condition: $95 \%$ probability of a significant difference between measured

430 pressure with and without fabric between the pressure mapping system and the table are different for the

431 five tested fabrics

432 Table 8. Results of surface condition: linear regression coefficient for the second and third surface

433 condition tests

434 Table 9. Results of mapping system superposition: $95 \%$ probability of a significant difference between

435 the mapping system "from above" and "from the bottom"

436 Table 10. Results of mapping system superposition: absolute differences between measured pressures

437 with or without superposition for each pressure mapping system 


\section{$439 \quad$ Figure captions}

$440 \quad$ Figure 1. FSA Pressure mapping system

441 Figure 2. Experimental device for the second hysteresis test

442 Figure 3. Experimental device for curvature test

443 Figure 4. Results of linearity: measured pressure depending on applied pressure for the sensor 1 of the 444 pressure mapping system A

445 Figure 5: Results of the second hysteresis test (test in all sensors of a pressure mapping system): mean

446 measured pressure depending on applied pressure for mapping system A

447 Figure 6. Results of drift: a. drift for $26 \mathrm{mmHg}$ applied pressure for mapping system A in the sensor 1 , b.

448 drift for $40 \mathrm{mmHg}$ applied pressure for mapping system $\mathrm{C}$ in the sensor 1, c. drift for $26 \mathrm{mmHg}$ applied 449 pressure for mapping system $\mathrm{D}$ in the sensor 3

450 Figure 7. Results of curvature: normalized measured pressure depending on applied pressure and radius of 451 cylinders Rc for mapping system A 
452 Table 1. Design of experiments to test the reproducibility of time, place and operators

\begin{tabular}{|c|c|c|c|c|}
\hline Experiments & $\begin{array}{c}\text { Time } \\
-1: \mathrm{t} 0 \\
+1: \text { t } 0+2 \text { months } \\
\end{array}$ & $\begin{array}{c}\text { Operators } \\
-1 \text { : operator A } \\
+1 \text { : operator B } \\
\end{array}$ & $\begin{array}{l}\text { Location } \\
\text {-1: place A } \\
+1 \text { : place B }\end{array}$ & $\begin{array}{c}\text { Weight } \\
-1: 53 \mathrm{mmHg} \\
+1: 79 \mathrm{mmHg} \\
\end{array}$ \\
\hline 1 & -1 & -1 & -1 & -1 \\
\hline 2 & +1 & -1 & -1 & -1 \\
\hline 3 & -1 & +1 & -1 & -1 \\
\hline 4 & +1 & +1 & -1 & -1 \\
\hline 5 & -1 & -1 & +1 & -1 \\
\hline 6 & +1 & -1 & +1 & -1 \\
\hline 7 & -1 & +1 & +1 & -1 \\
\hline 8 & +1 & +1 & +1 & -1 \\
\hline 9 & -1 & -1 & -1 & +1 \\
\hline 10 & +1 & -1 & -1 & +1 \\
\hline 11 & -1 & +1 & -1 & +1 \\
\hline 12 & +1 & +1 & -1 & +1 \\
\hline 13 & -1 & -1 & +1 & +1 \\
\hline 14 & +1 & -1 & +1 & +1 \\
\hline 15 & -1 & +1 & +1 & +1 \\
\hline 16 & +1 & +1 & +1 & +1 \\
\hline
\end{tabular}


455 Table 2. Results of linearity: linear regression coefficient and p-value of the Student's t-test on slope=0

\begin{tabular}{|c|c|c|c|c|}
\hline $\begin{array}{r}\text { Mapping } \\
\text { system }\end{array}$ & $\mathrm{A}$ & $\mathrm{B}$ & $\mathrm{C}$ & $\mathrm{D}$ \\
\hline \multirow{2}{*}{1} & $\mathrm{R}^{2}=0.978$ & $\mathrm{R}^{2}=0.962$ & $\mathrm{R}^{2}=0.982$ & $\mathrm{R}^{2}=0.967$ \\
& $\mathrm{p}=4.7 \mathrm{e}-6$ & $\mathrm{p}=8.8 \mathrm{e}-6$ & $\mathrm{p}=2.6 \mathrm{e}-8$ & $\mathrm{p}=2.1 \mathrm{e}-5$ \\
\hline 2 & $\mathrm{R}^{2}=0.961$ & $\mathrm{R}^{2}=0.954$ & $\mathrm{R}^{2}=0.936$ & $\mathrm{R}^{2}=0.967$ \\
& $\mathrm{p}=8.1 \mathrm{e}-5$ & $\mathrm{p}=1.0 \mathrm{e}-4$ & $\mathrm{p}=2.3 \mathrm{e}-4$ & $\mathrm{p}=2.5 \mathrm{e}-5$ \\
\hline 3 & $\mathrm{R}^{2}=0.972$ & $\mathrm{R}^{2}=0.951$ & $\mathrm{R}^{2}=0.964$ & $\mathrm{R}=0.862$ \\
& $\mathrm{p}=4.3 \mathrm{e}-7$ & $\mathrm{p}=3.9 \mathrm{e}-5$ & $\mathrm{p}=3.5 \mathrm{e}-7$ & $\mathrm{p}=9.0 \mathrm{e}-4$ \\
\hline
\end{tabular}

456 
457 Table 3. Results of linearity: Dispersion and standard deviation for sensors with the best and the worst 458 linearity.

\begin{tabular}{|c|c|c|c|}
\hline Sensors & Applied pressure (mmHg) & Dispersion (mmHg) & Standard deviation \\
\hline \multirow{7}{*}{$\begin{array}{l}\text { With the best linearity: } \\
\text { sensor } 1 \text {, mapping } \\
\text { system C }\end{array}$} & 6.4 & 0 & 0 \\
\hline & 13 & 1.74 & 0.641 \\
\hline & 26 & 3.32 & 2.35 \\
\hline & 39 & 2.97 & 1.54 \\
\hline & 53 & 3.99 & 1.97 \\
\hline & 79 & 9.05 & 3.22 \\
\hline & 96 & 15.6 & 6.30 \\
\hline \multirow{7}{*}{$\begin{array}{c}\text { With the worst linearity: } \\
\text { sensor } 3 \text {, mapping } \\
\text { system C }\end{array}$} & 6.4 & 0 & 0 \\
\hline & 13 & 0.103 & 0.0201 \\
\hline & 26 & 0.120 & 0.0320 \\
\hline & 39 & 1.01 & 0.376 \\
\hline & 53 & 1.74 & 0.775 \\
\hline & 79 & 4.35 & 1.97 \\
\hline & 96 & 5.52 & 3.08 \\
\hline
\end{tabular}

459

460 
461 Table 4: Results of hysteresis: test in only one sensor per mapping system

\begin{tabular}{|c|c|c|c|c|c|c|c|c|c|c|c|c|c|c|c|c|}
\hline Mapping & \multicolumn{8}{|c|}{ A } & \multicolumn{8}{|c|}{ B } \\
\hline Sensor & 1 & 2 & 3 & 4 & 5 & 6 & 7 & 8 & 1 & 2 & 3 & 4 & 5 & 6 & 7 & 8 \\
\hline $\begin{array}{c}\text { Hysteresis } \\
\text { Eh }(\%)\end{array}$ & 15.2 & 16.9 & 7.63 & 4.58 & 11.9 & 7.84 & 16.1 & 10.1 & 3.51 & 6.38 & 11.7 & 0.228 & 18.3 & 15.7 & 27.9 & 9.20 \\
\hline $\begin{array}{c}\text { Mapping } \\
\text { system }\end{array}$ & \multicolumn{8}{|c|}{$\mathrm{C}$} & \multicolumn{8}{|c|}{$\mathrm{D}$} \\
\hline Sensor & 1 & 2 & 3 & 4 & 5 & 6 & 7 & 8 & 1 & 2 & 3 & 4 & 5 & 6 & 7 & 8 \\
\hline $\begin{array}{c}\text { Hysteresis } \\
\text { Eh }(\%)\end{array}$ & 3.99 & 4.53 & 7.13 & 2.80 & 5.26 & 3.15 & 9.93 & 2.70 & 6.52 & 3.15 & 3.66 & 3.63 & 2.27 & 3.99 & 10.5 & 7.20 \\
\hline
\end{tabular}

462

463 
464 Table 5. Results of hysteresis: test in all sensors per mapping system

\begin{tabular}{|c|c|c|c|c|}
\hline Mapping system & A & B & C & D \\
\hline Hysteresis Eh (\%) & 9.41 & 7.87 & 7.58 & 6.29 \\
\hline
\end{tabular}

465

466 
467 Table 6. Results of the design of experiments for reproducibility. t: time, o: operators, l: location, w:

468 weight

\begin{tabular}{|c|c|c|}
\hline Polynomial coefficient & Value & Probability \\
\hline$\beta_{0}$ & 67.76 & 0 \\
\hline$\beta_{\mathrm{t}}$ & 0.28 & 0.70 \\
\hline$\beta_{o}$ & 1.47 & 0.054 \\
\hline$\beta_{1}$ & 2.08 & 0.0080 \\
\hline$\beta_{\mathrm{w}}$ & 19.19 & 0 \\
\hline$\beta_{\text {to }}$ & 1.94 & 0.0013 \\
\hline$\beta_{\mathrm{tl}}$ & -3.84 & 0 \\
\hline$\beta_{\mathrm{tw}}$ & -0.17 & 0.82 \\
\hline$\beta_{\mathrm{ol}}$ & 0.66 & 0.38 \\
\hline$\beta_{\text {ow }}$ & 1.24 & 0.10 \\
\hline$\beta_{\mathrm{tw}}$ & -0.73 & 0.33 \\
\hline
\end{tabular}

469

470 
471 Table 7. Results of surface condition: p_value of the statistical test to determine the statistically

472 significant differences between measured pressure with and without fabric between the pressure mapping 473 system and the table.

474

\begin{tabular}{|c|c|c|c|c|c|}
\hline Fabric & 1 & 2 & 3 & 4 & 5 \\
\hline & $2.97 \mathrm{e}^{-21}$ & $3.36 \mathrm{e}^{-18}$ & $3.77 \mathrm{e}^{-47}$ & $2.48 \mathrm{e}^{-31}$ & $8.17 \mathrm{e}^{-57}$ \\
\hline
\end{tabular}


475 Table 8. Results of surface condition: linear regression coefficient for the second and third surface

476 condition tests

\begin{tabular}{|c|c|c|c|c|}
\hline Sensors & 1 & 2 & 5 & 7 \\
\hline $\begin{array}{c}\text { Second surface } \\
\text { condition test }\end{array}$ & 0.97 & 0.95 & 0.97 & 0.99 \\
\hline $\begin{array}{c}\text { Third surface } \\
\text { condition test }\end{array}$ & 0.92 & 0.93 & 0.98 & 0.95 \\
\hline
\end{tabular}

477 
478 Table 9. Results of mapping system superposition: p_value of the statistical test to determine the

479 statistically significant differences between mapping system "from above" and "from the bottom"

\begin{tabular}{|c|c|c|c|}
\hline Sensors & 1 & 2 & 3 \\
\hline $\begin{array}{c}\text { Between mapping } \\
\text { system A: "from above" } \\
\text { and mapping system B: } \\
\text { "from the bottom" }\end{array}$ & 0.010 & 0.43 & 0.038 \\
\hline $\begin{array}{c}\text { Between mapping } \\
\text { system C: "from above" } \\
\text { and mapping system D: } \\
\text { "from the bottom" }\end{array}$ & 0.0041 & 0.015 & 0.0058 \\
\hline
\end{tabular}

480 
481 Table 10. Results of mapping system superposition: absolute differences between measured pressures

482 with or without superposition for each pressure mapping system in $\mathrm{mmHg}$

\begin{tabular}{|c|c|c|c|c|}
\hline Mapping system & A & B & C & D \\
\hline Sensor 1 & 10.3 & 14.6 & 3.94 & 4.16 \\
\hline Sensor 2 & 14.0 & 12.5 & 2.97 & 2.48 \\
\hline Sensor 3 & 9.32 & 23.0 & 9.64 & 2.75 \\
\hline
\end{tabular}

483

484 
485 Table 11. Comparison between the studied pressure mapping system and other commercial systems based 486 on literature survey: resistive pressure mapping systems.

\begin{tabular}{|c|c|c|c|c|c|c|}
\hline $\begin{array}{c}\text { Mapping } \\
\text { system }\end{array}$ & FSA & $\begin{array}{c}\text { Tekscan's } \\
\text { Flexiforce } \\
\text { reference }\end{array}$ & $\begin{array}{c}\text { Tekscan's F- } \\
\text { Socket } \\
{[22]}\end{array}$ & $\begin{array}{c}\text { Tekscan's } \\
\text { F-Scan } \\
{[25]}\end{array}$ & Rincoe & Lück \\
\hline $\begin{array}{c}\text { Measurement } \\
\text { error }\end{array}$ & $12.6 \%$ & $\begin{array}{c}{[5.62 \%,} \\
26.3 \%]\end{array}$ & $8.5 \pm 7.2 \%$ & $247 \%$ & $24.7 \pm 19.02 \%$ & $-33 \%$ \\
\hline Hysteresis & $\begin{array}{c}{[6.29 \%,} \\
9.41 \%]\end{array}$ & $5.4 \pm 2.5 \%$ & $41.9 \pm 15 \%$ & - & $15.1 \pm 8 \%$ & - \\
\hline
\end{tabular}

487 


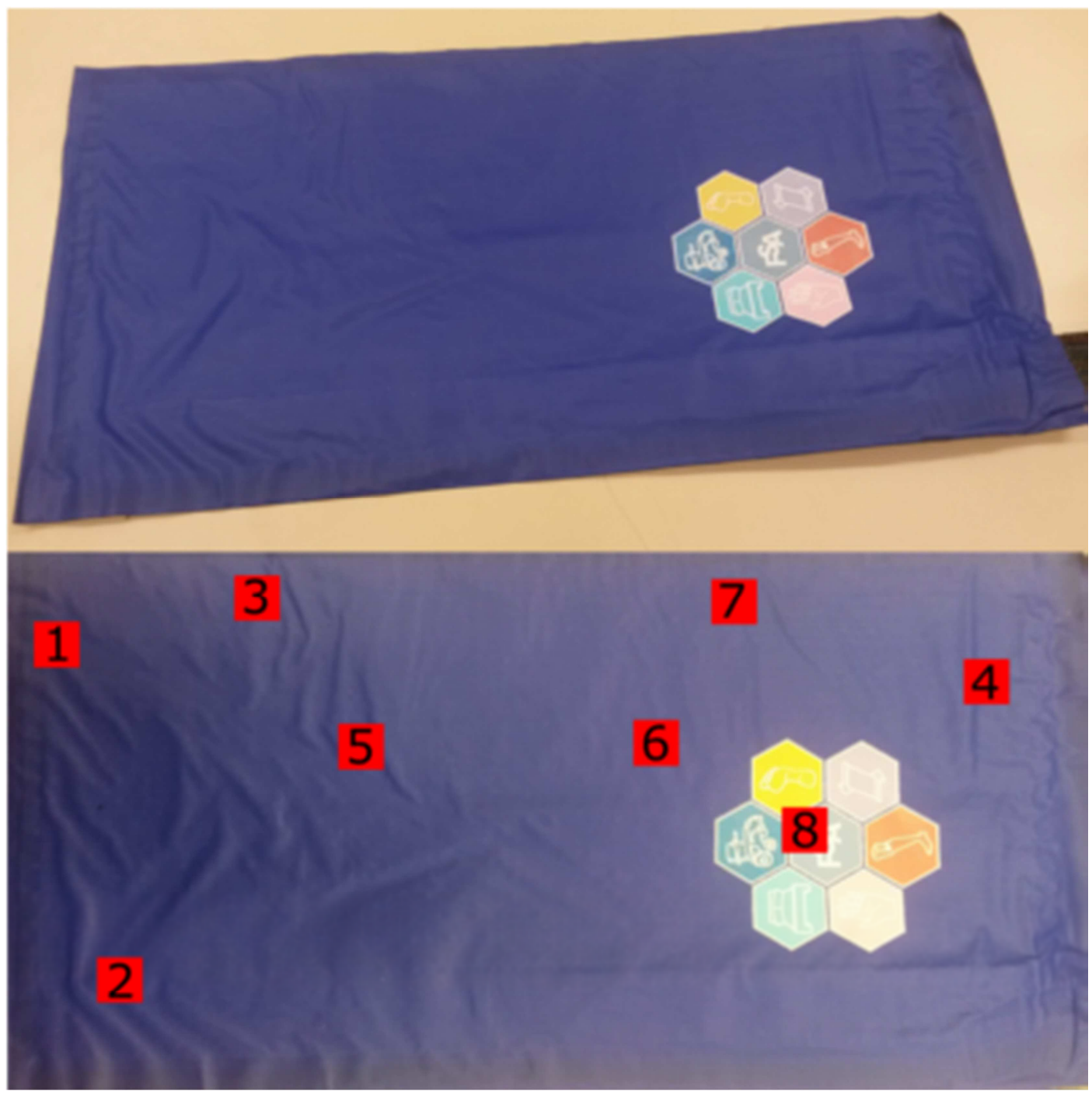


(b) Device in used, with one pressure mapping system inside

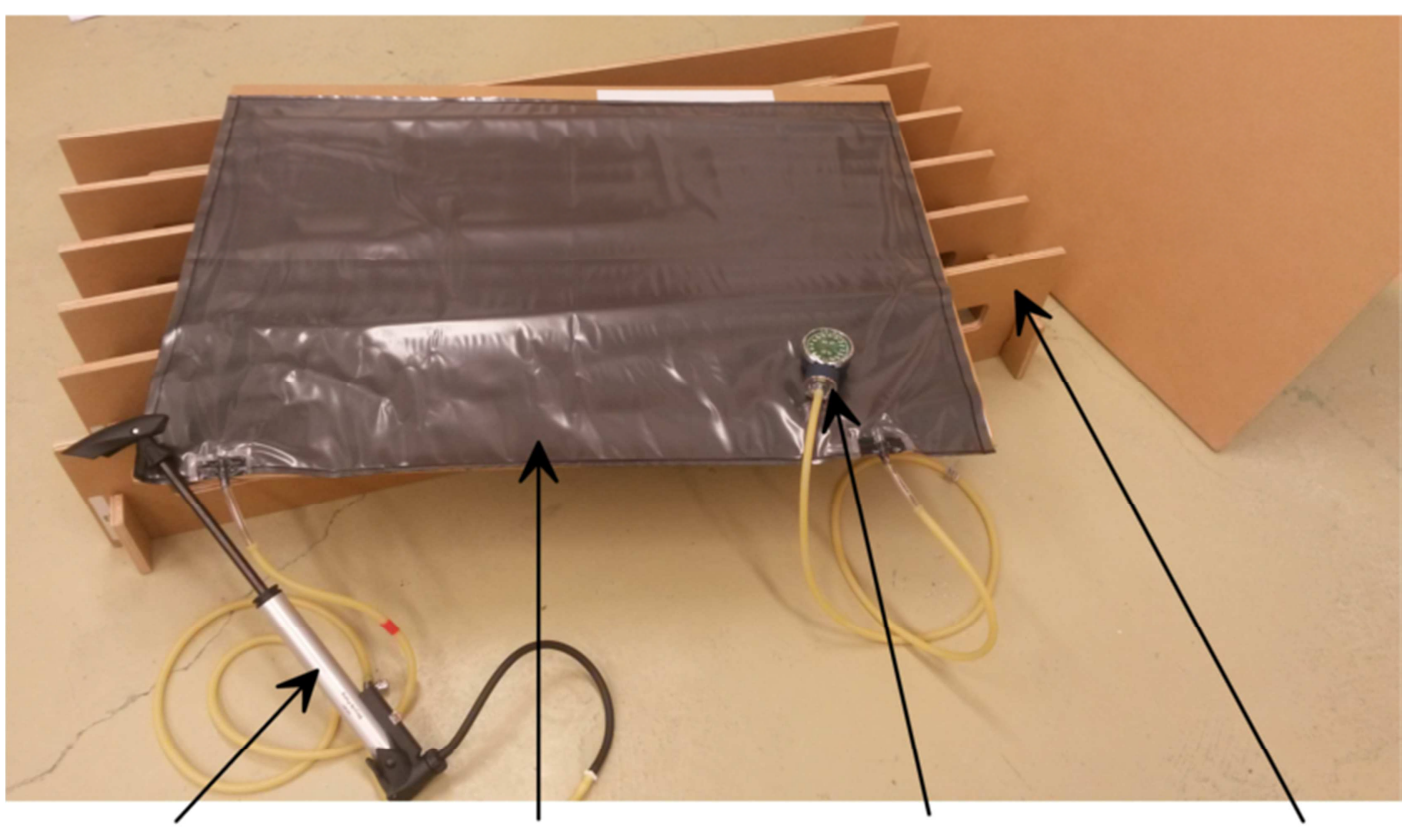

\section{Air pump Air pocket Manometer Support}

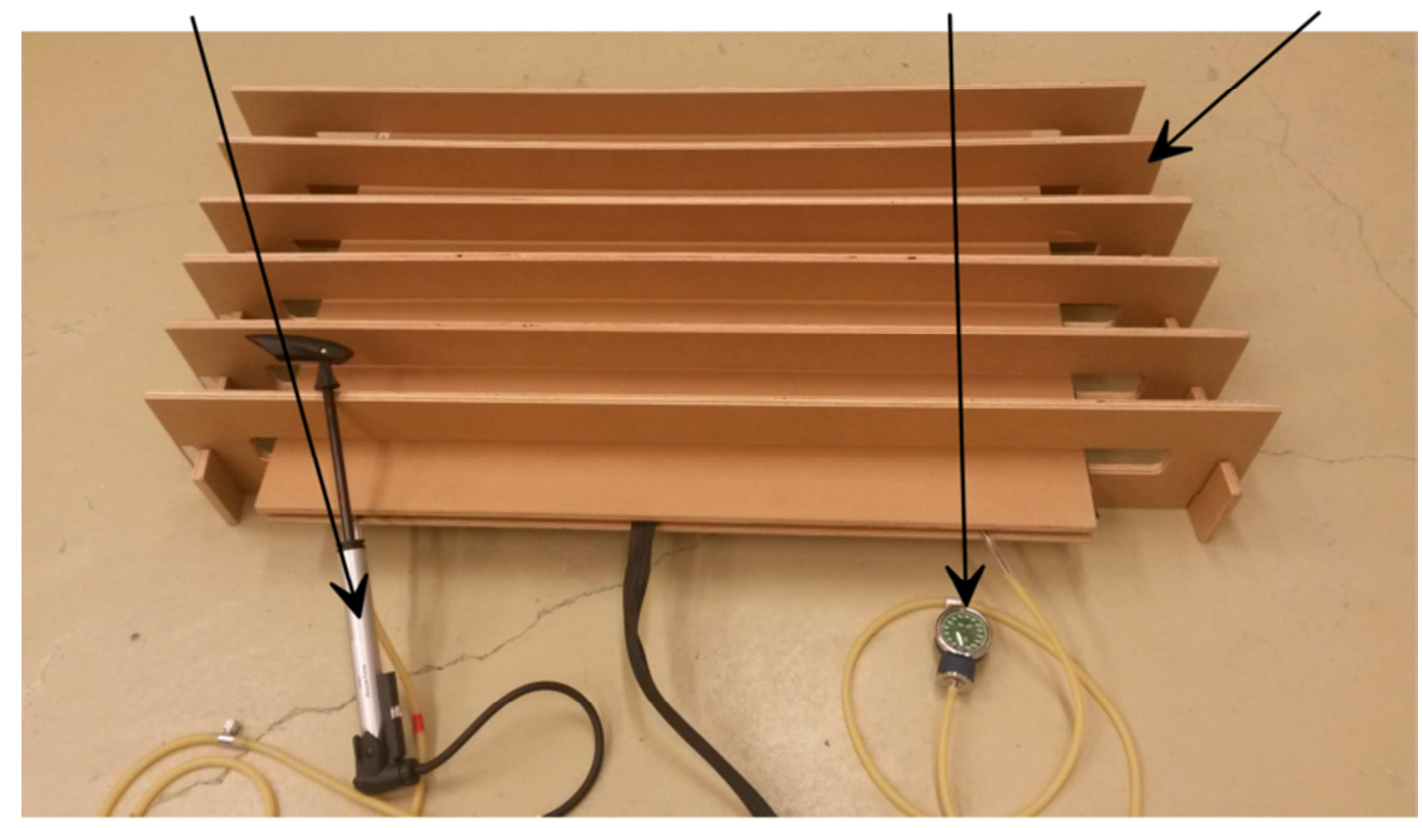




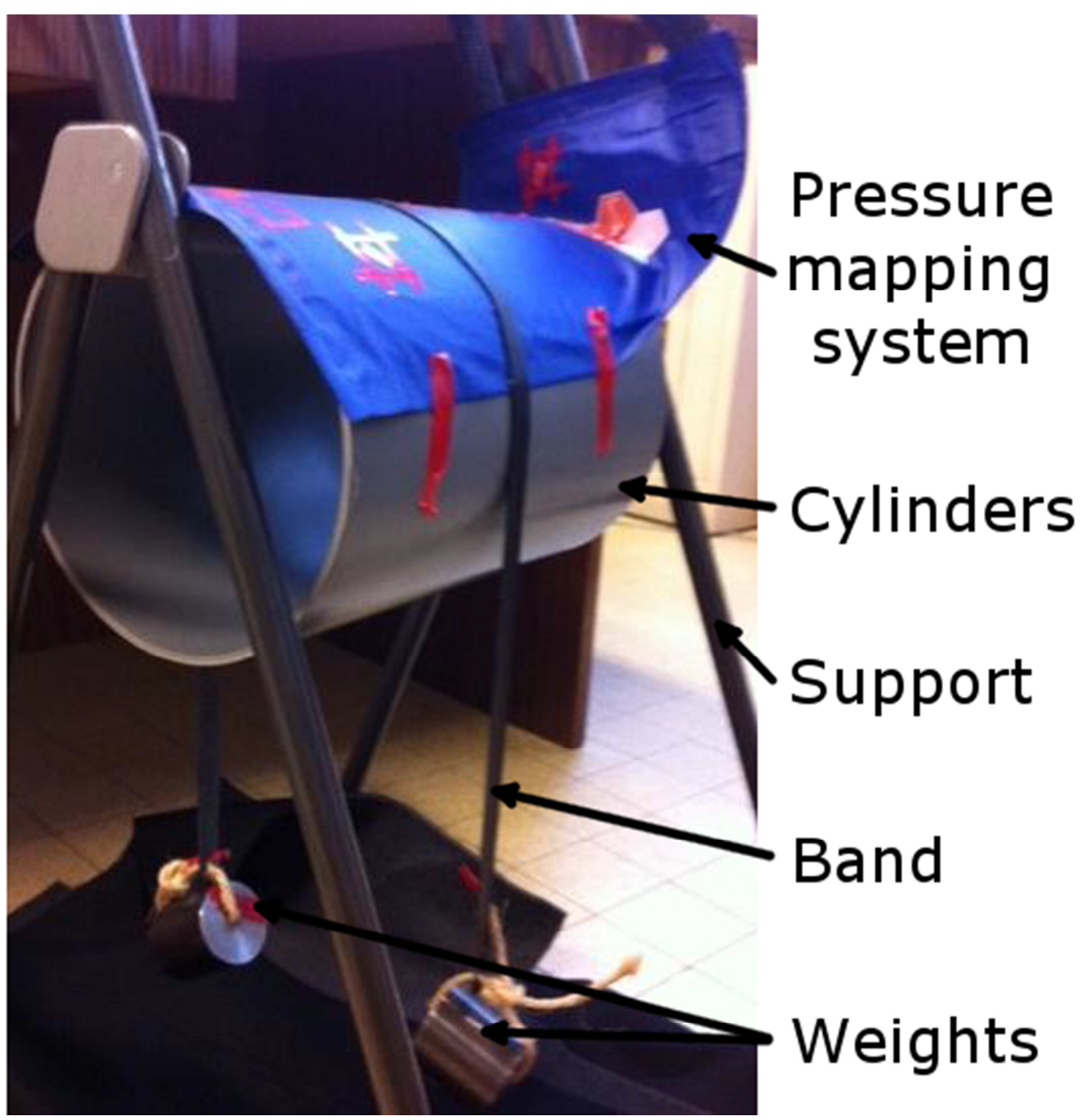


495 Figure 4. Results of linearity: measured pressure depending on applied pressure for the sensor 1 of the 496 pressure mapping system C

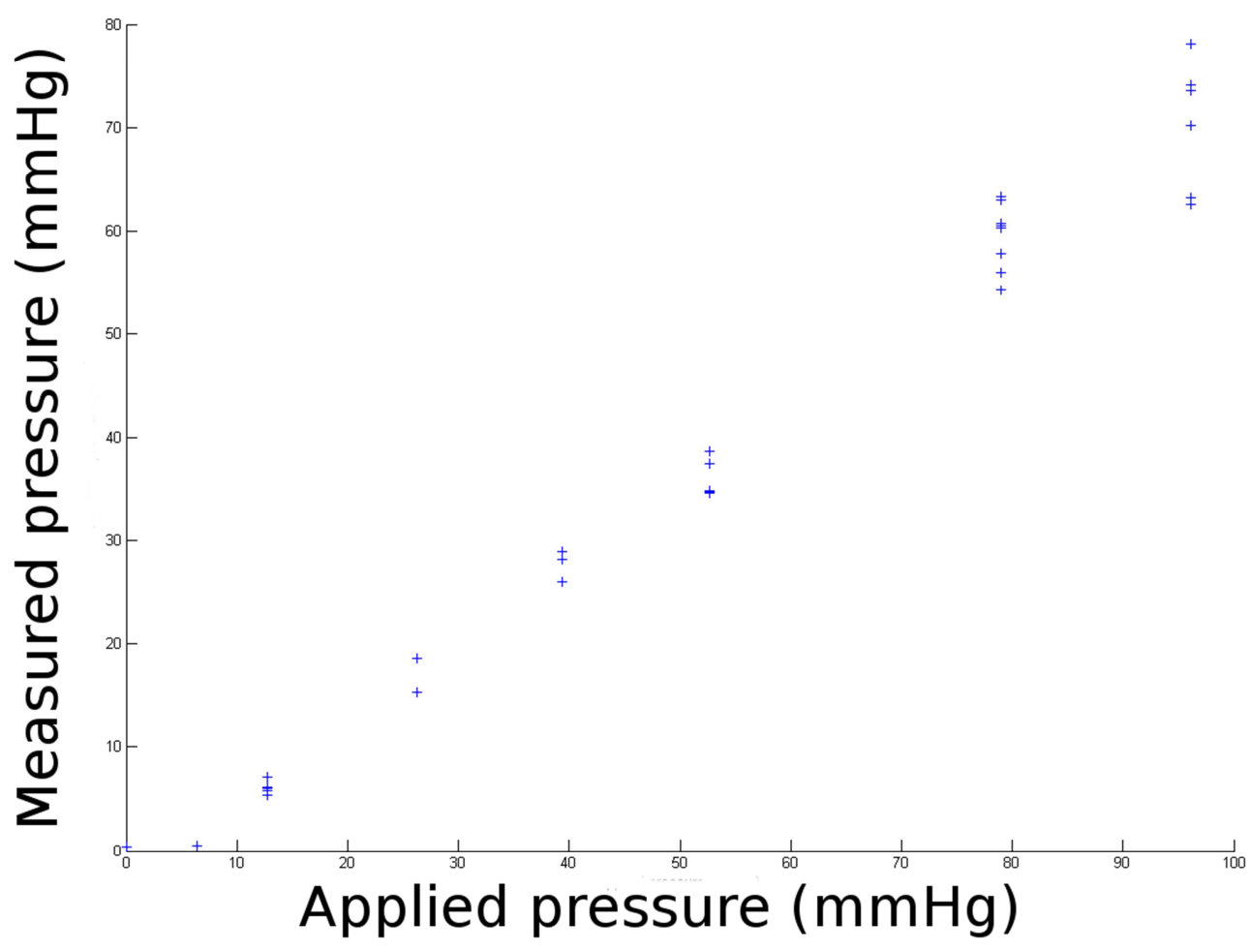

497 
498 Figure 5: Results of the second hysteresis test (test in all sensors of a pressure mapping system): mean

499 measured pressure depending on applied pressure for mapping system A

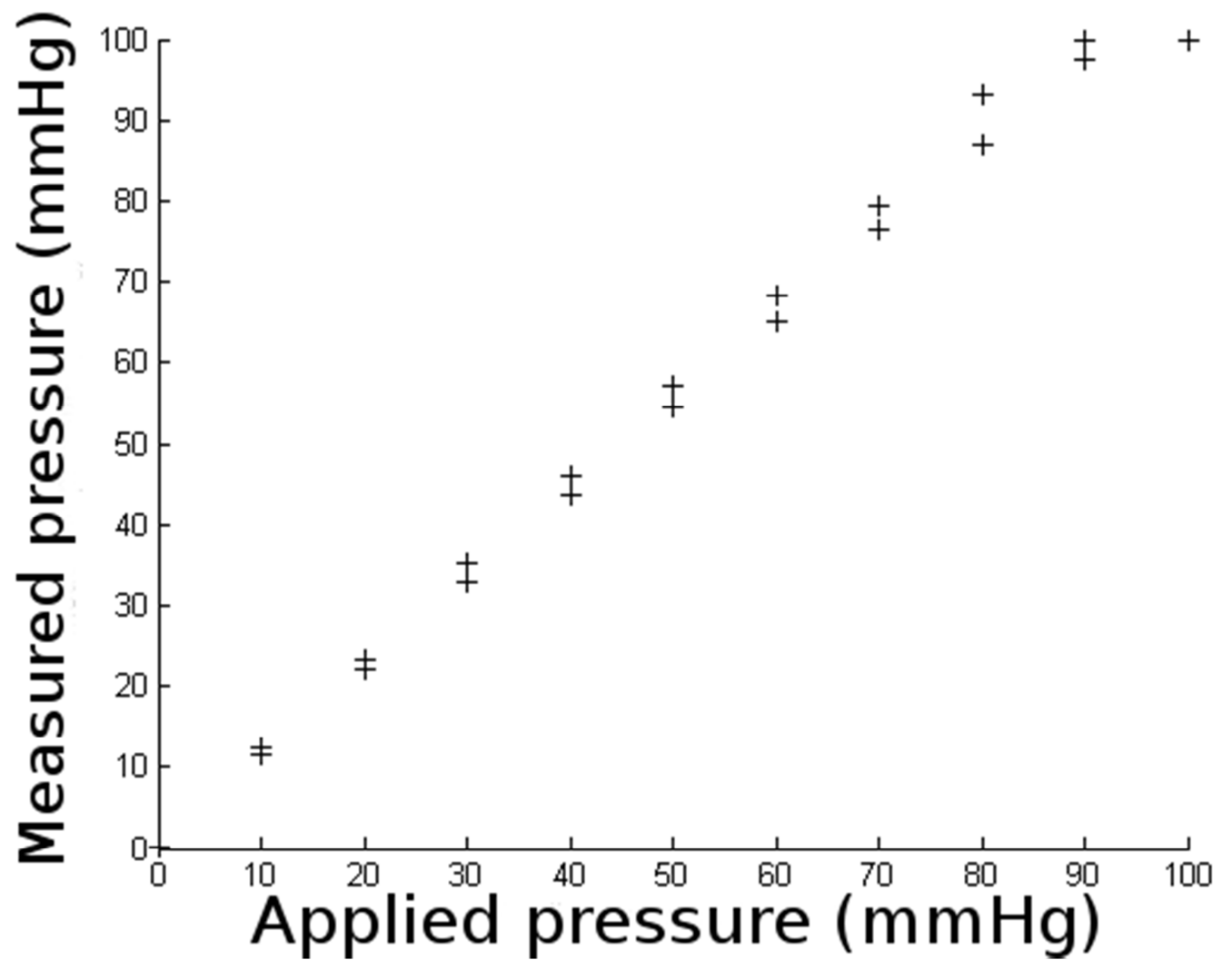


501 Figure 6. Results of drift: (a) drift for $26 \mathrm{mmHg}$ applied pressure for mapping system A in the sensor 1 ,

502 (b) drift for $40 \mathrm{mmHg}$ applied pressure for mapping system $\mathrm{C}$ in the sensor 1, (c) drift for $26 \mathrm{mmHg}$

503 applied pressure for mapping system D in the sensor 3

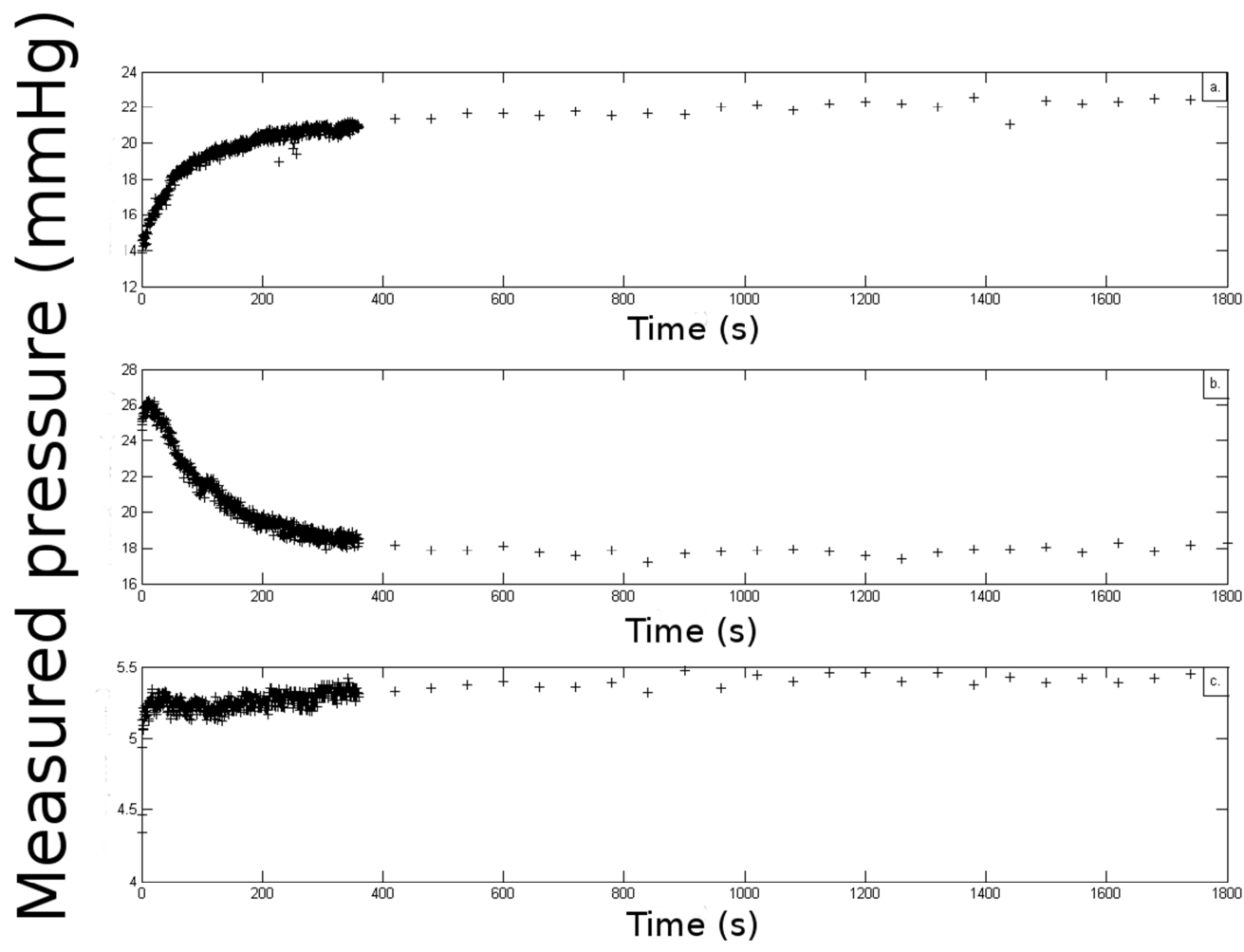


505 Figure 7. Results of curvature: normalized measured pressure depending on applied pressure and radius of

506 cylinders Rc for mapping system A

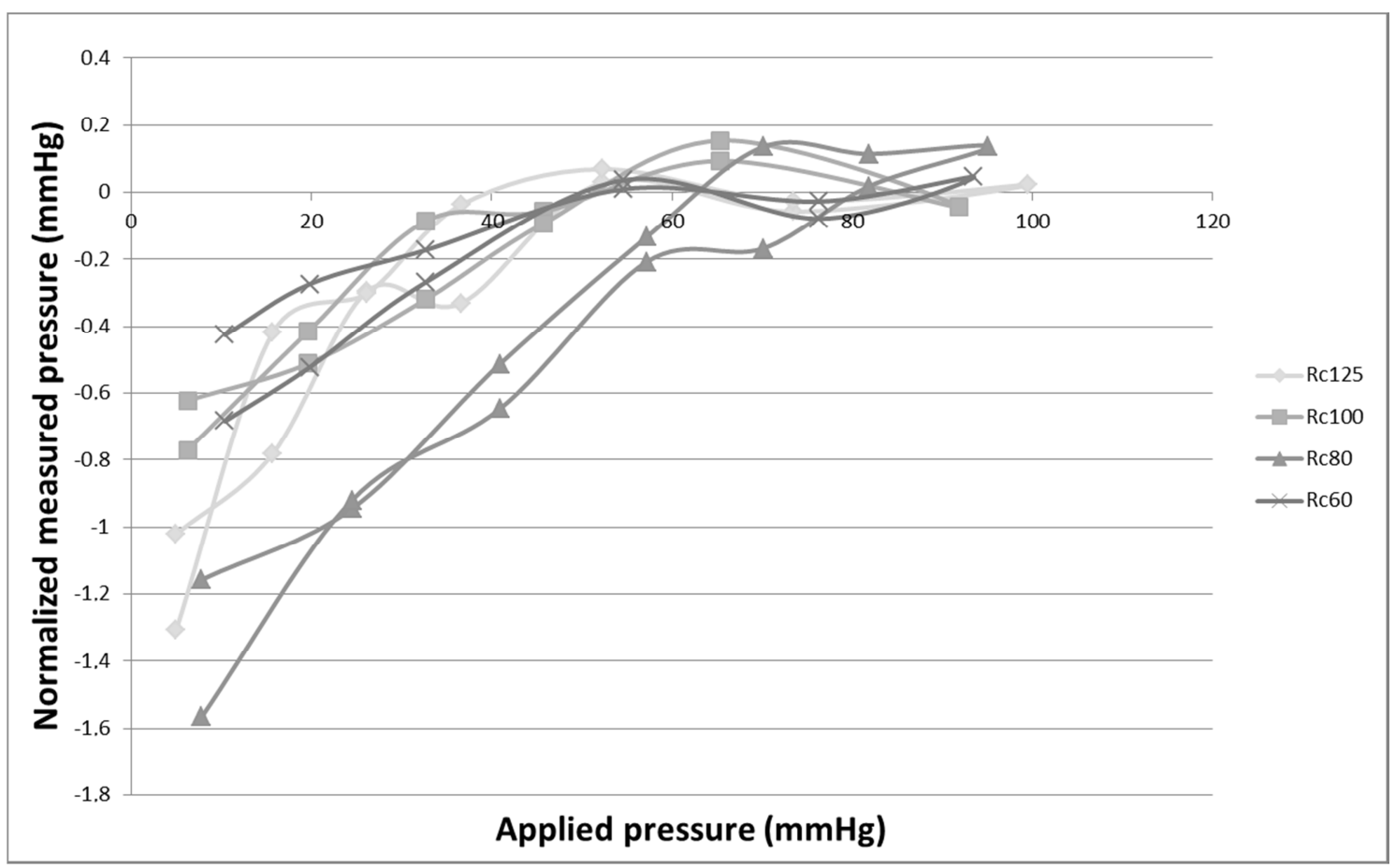

